\title{
Risk of "silent stroke" in patients older than 60 years: risk assessment and clinical perspectives
}

This article was published in the following Dove Press journal:

Clinical Interventions in Aging

I September 2010

Number of times this article has been viewed

\author{
Jae-Sung Lim' \\ Hyung-Min Kwon ${ }^{2}$
}

'Department of Neurology, Armed Forces Seoul Hospital, Seoul, Republic of Korea; ${ }^{2}$ Department of Neurology, Seoul National University Boramae Hospital, Seoul, Republic of Korea
Correspondence: Hyung-Min Kwon Seoul National University Boramae Hospital, Department of Neurology, Seoul National University College of Medicine, 39 Boramae-gil, Dongjak-gu, Seoul 156-707, South Korea

Tel +82-2-870-2475

Fax +82-2-83I-2826

Email hmkwon@snu.ac.kr
Abstract: With the increasing size of the elderly population and evolving imaging technology, silent brain infarction (SBI) has garnered attention from both the public and the physicians. Over $20 \%$ of the elderly exhibit SBI, and the prevalence of SBI increases steadily with age, ie, $30 \%-40 \%$ in those older than 70 years. Well-known cardiovascular risk factors such as hypertension has been identified as a risk factor of SBI (odds ratio $[\mathrm{OR}]=3.47$ ) Besides this, blood pressure $(\mathrm{BP})$ reactivity to mental stress, morning BP surges, and orthostatic BP changes have been demonstrated to contribute to the presence of SBI. Further, a metabolic syndrome not only as a whole syndrome $(\mathrm{OR}=2.18)$ but also as individual components could have an influence on SBI. Increased C-reactive protein and interleukin-6, coronary artery disease, body mass index, and alcohol consumption have also been associated with SBI. The ORs and possible mechanisms have been discussed in this article. Overt stroke, dementia, depression, and aspiration pneumonia were all associated with SBI. (overt stroke: hazard ratio $[\mathrm{HR}]=1.9,95 \%$ confidence interval [CI]: 1.2-2.8; dementia: $\mathrm{HR}=2.26,95 \% \mathrm{CI}: 1.09-4.70)$. We also looked into their close relationship with $\mathrm{SBI}$ in this review.

Keywords: silent brain infarction, elderly, risk factors, treatment

\section{Introduction}

Silent stroke, and in particular, silent brain infarction (SBI), is a term owing to recent developments in cerebral imaging. As more healthy people undergo routine screening imaging as part of health evaluations, more SBIs are being detected in people of all ages. Because of the significance of stroke as the leading cause of disability and mortality, SBI has garnered a lot of attention from both the public and the clinicians.

With increasing life expectancy, elderly people can expect to survive several years or even decades longer than previously. Therefore, SBI is becoming a main concern for them. How often is SBI detected in the elderly? What are the age-specific incidences? Which risk factors contribute to the presence of SBI? Does SBI really lead to more serious health problems such as stroke? These are the kind of questions that are still unanswered and for which several researchers have been diligently trying to resolve. ${ }^{1}$

In this article, the current knowledge of SBI has been discussed including the working definition, as well as its epidemiology, risk factors, and health consequences, particularly in the elderly.

\section{Methods}

We did a literature search in PubMed using the terms silent brain infarction, silent cerebral infarction, silent lacunar infarction, and asymptomatic cerebral infarction. 
Those studies that involved subjects older than 60 years of age were included. For the others, we reviewed and referenced these for the sake of comparison. Referenced articles were limited to the full-text papers published in English over an unlimited period of time.

\section{Criteria for SBI}

The definition of SBI was inconsistent throughout the articles. SBI was usually defined as focal T2 hyperintensities $>3 \mathrm{~mm}$ with correlative T1 hypointensities. ${ }^{1,2}$ However, there were several discrepancies about the size and the presence of correlative T1 hypointensities. ${ }^{3}$ Also, in some studies, authors divided the lesions into 3 groups: SBI (focal T2 hyperintensities $>3 \mathrm{~mm}$ with correlative T1 hypointensity), focal white matter T2 hyperintensity lesions (FWT2HLs) similar to SBI but without correlative T1 hypointensity, and periventricular hyperintensity $(\mathrm{PVH})$ using magnetic resonance imaging (MRI). ${ }^{2}$

Further, clinicians sometimes misinterpreted the Virchow-Robin spaces as SBI. In one study by a Japanese study group, ${ }^{3}$ discriminating characteristics were described using MRI. Authors pointed that SBI was different from Virchow-Robin spaces in locations, shapes, and sizes. Among them, the size was the most important discriminating factor. For the most part, Virchow-Robin spaces were $<2 \times 1 \mathrm{~mm}$. Further, SBI was wedge-shaped, whereas the Virchow-Robin spaces were round or linear. The locations of the lesions also should be considered in the differentiation. If lesions were located in the brainstem, SBI was more probable than Virchow-Robin spaces. In basal ganglia, other than in the lower part, SBI was more probable than Virchow-Robin space in lesions $>3 \times 2 \mathrm{~mm}$. In the lower part of basal ganglia, the discrimination was not easy, so the proton density image, shape of the lesion, and symmetry of their distribution should be considered prior to the decision. ${ }^{3,4}$ If the lesions were located in the subcortical area and hypointense on T1 images, those lesions should be classified as SBI. ${ }^{5}$

In summary, SBI can be defined as focal T2 hyperintense lesions $>3 \mathrm{~mm}$, which are mostly hypointense on T1 images. ${ }^{5}$ Their size, shape, and locations are all needed to differentiate them from other anatomical structures such as VirchowRobin spaces (Figure 1).

\section{Epidemiology of SBI - incidence}

The incidence of SBI could be assumed by the Rotterdam Scan Study. ${ }^{6}$ Of 1,077 participants aged 60-90 years, 668 subjects were followed up for 3.4 years on average by MRI. Ninety-three subjects (14\%) showed one or more newly-detected lesions in the second MRI. Among them, 81 $(12 \%)$ had SBI, and the remaining had symptomatic lesions. Those who had SBI on baseline MRI tended to have new lesions on follow-up (age-adjusted and sex-adjusted odds ratio $[\mathrm{OR}]=2.9 ; 95 \%$ confidence interval $[\mathrm{CI}]: 1.7-5.0)$. The cumulative incidence over 3.4 years was increased according to age resulting in $8 \%$ in subjects of 60 and 70 years and $22 \%$ in subjects older than 80 years.

A cardiovascular health study was conducted in 1,433 participants who were older than 65 years. ${ }^{7}$ They were followed up for 5 years and underwent MRI scans. A total of 225 subjects $(15.7 \%)$ showed new infarctions on MRI without definite focal neurologic deficits. The authors classified them as covert infarcts rather than silent because they showed decreased scores on the modified minimental state examination and digit symbol substitution test (both $P<0.01$ ).

\section{Epidemiology of SBI - prevalence}

In the Rotterdam Scan Study, 259 subjects (24\%) among 1,077 participants showed one or more infarct lesions at baseline. ${ }^{8}$ Further, 217 (20\%) had silent lesions, 26 (2.4\%) symptomatic, and $16(1.5 \%)$ had both. The prevalence increased with ages. In the 60-year-old to 64-year-old group, the prevalence was $8 \%$, whereas it was up to $35 \%$ in the 85 -year-old to 90 -year-old group. SBI was more common in the female group (age-adjusted $\mathrm{OR}=1.4 ; 95 \% \mathrm{CI}$ : $1.0-1.8$ ). In a study of 153 community-dwelling elderly, older than 66 years, which looked at their plasma homocysteine ( $\mathrm{pHcy}$ ) levels and methylenetetrahydrofolate reductase (MTHFR) gene, SBI was detected in $24.8 \%$ of subjects. ${ }^{9}$ Autopsies were conducted in a Japanese community-based study. ${ }^{10}$ In 26 years, from 1961 to 1987, 966 subjects in Kyushu, Hisayama, were enrolled into this study. Subjects who were older than 40 years were included, and the mean age at autopsy was 78 years (range, 42-97 years; mean \pm standard deviation [SD], $78.3 \pm 9.5$ years). SBI was detected in $12.9 \%$ of patients. ${ }^{11}$

For comparison, only 88 (5.5\%) subjects showed SBI among 1,588 neurologically healthy adults (927 males and 661 females; mean age 53.6 years) who underwent brain MRIs at a university hospital healthcare center. ${ }^{12}$ Another study revealed similar prevalence resulting in an age-adjusted SBI prevalence of 5.1\% among 994 healthy adults (mean age $49.0 \pm 7.7){ }^{13}$

There were considerable discrepancies in the prevalence rates listed in these studies due to differences in age distribution and the presence of underlying cardiovascular diseases in the study population (Table 1). However, it was evident 
A

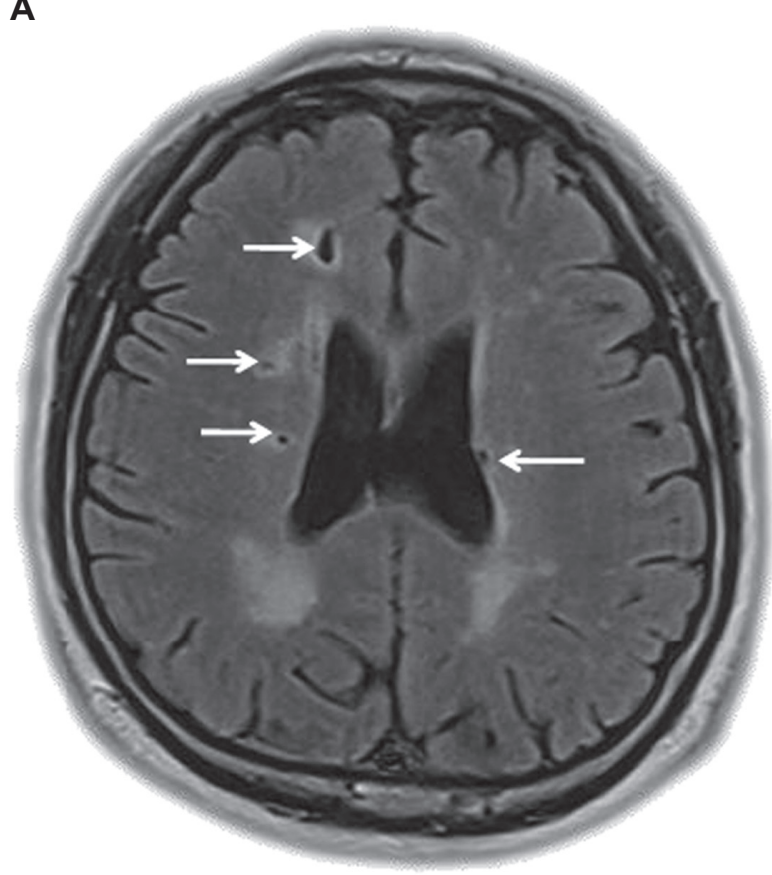

C

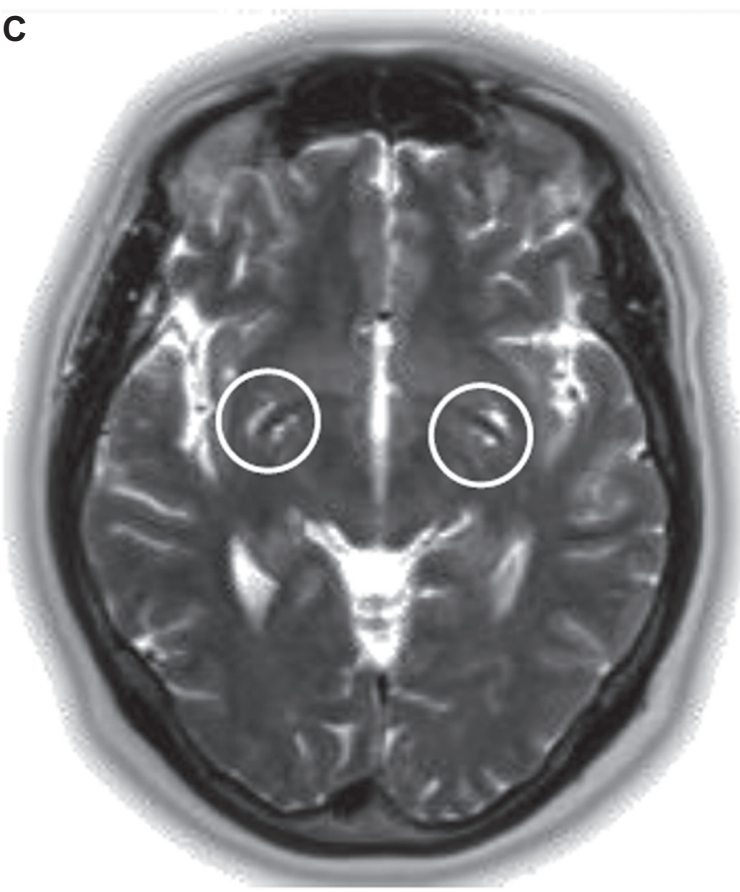

B

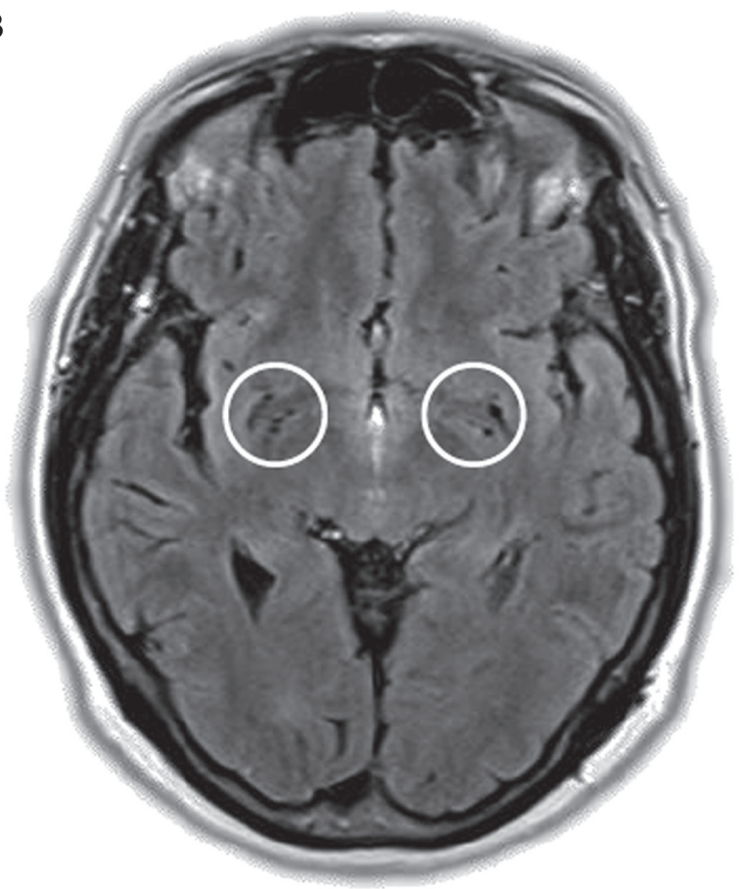

D

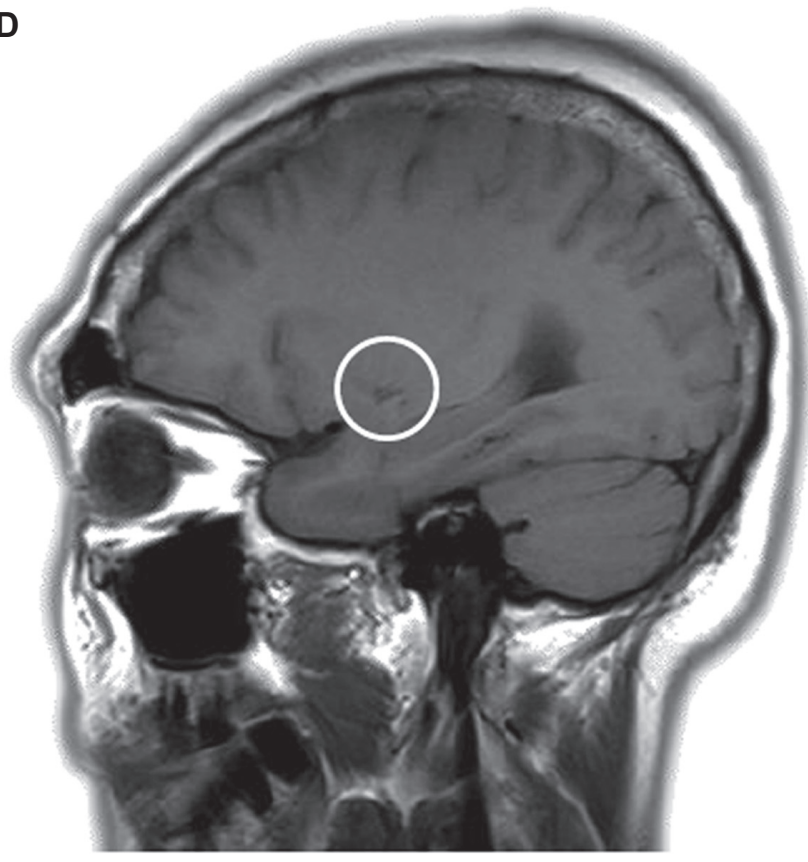

Figure I Magnetic resonance imaging from patients with silent brain infarctions and Virchow-Robin spaces: (A) several silent brain infarctions (arrow) in the axial image of the FLAIR sequence; (B-D) numerous Virchow-Robin spaces in the basal ganglia (circle) in the FLAIR axial, T2-weighted axial, and TI-weighted saggital images.

that the prevalence showed increments between the ages 60 and 80 years.

\section{Epidemiology of SBI in patients with comorbidity}

The prevalence of SBI in the patients with various diseases also should be considered. In the community-based study, the presence of chronic kidney disease (CKD) and SBI showed significant associations in the elderly $(\mathrm{OR}=1.86) \cdot{ }^{14}$ In the patients with CKD, the prevalence of SBI was $56.5 \%$, and it showed a significant inverse correlation with the estimated glomerular filtration rate. ${ }^{15}$ In another study, $25 \%$ of patients with a creatinine clearance $(\mathrm{CCr})>40 \mathrm{~mL} / \mathrm{min} / 1.73 \mathrm{~m}^{2}$ showed SBI, $85 \%$ with a $\mathrm{CCr}<40 \mathrm{~mL} / \mathrm{min} / 1.73 \mathrm{~m}^{2}$, and $29 \%$ with control with 
Table I Prevalence of SBI

\begin{tabular}{|c|c|c|c|c|c|c|c|c|}
\hline \multirow[t]{3}{*}{ Study } & \multirow[t]{3}{*}{ Population/subjects } & \multirow{3}{*}{$\begin{array}{l}\text { Mean age, y } \\
\text { (range) }\end{array}$} & \multirow[t]{3}{*}{$\mathbf{N}$} & \multicolumn{4}{|c|}{ Prevalence, \% } & \multirow[t]{2}{*}{ Reference } \\
\hline & & & & \multirow[t]{2}{*}{ Total } & \multicolumn{3}{|c|}{ Age, y } & \\
\hline & & & & & $60 \mathrm{~s}$ & $70 \mathrm{~s}$ & $80 \mathrm{~s}$ & \\
\hline Rotterdam scan study & $\begin{array}{l}\text { Community-dwelling, } \\
\text { nondemented elderly people }\end{array}$ & $76 \pm 7(60-90)$ & I,077 & 20 & 8 & & 35 & 8 \\
\hline Matsui et al (Japan) & $\begin{array}{l}\text { Community-dwelling, } \\
\text { nondemented elderly } \\
\text { older than } 66 \text { y }\end{array}$ & $76.7 \pm 5.3(66-88)$ & 153 & 24.8 & & & & 9 \\
\hline $\begin{array}{l}\text { Hisayama study } \\
\text { (Kyushu, Japan) }\end{array}$ & $\begin{array}{l}\text { Community-based } \\
\text { autopsy study }\end{array}$ & $78.3 \pm 9.5(42-97)$ & 966 & 12.6 & & & & 10 \\
\hline $\begin{array}{l}\text { Kwon et al } \\
\text { (Seoul, Korea) }\end{array}$ & $\begin{array}{l}\text { Healthy subjects for routine } \\
\text { health check, no history } \\
\text { of stroke or TIA }\end{array}$ & $69.8(65-96)$ & 1,254 & 15.7 & 11.7 & 18.0 & $27.6(>75)$ & 40 \\
\hline SMART study & $\begin{array}{l}\text { Patients with vascular disease } \\
\text { except stroke and transient } \\
\text { ischemic attack }\end{array}$ & $58(18-79)$ & 308 & 17 & & & & 11 \\
\hline $\begin{array}{l}\text { Kwon et al } \\
\text { (Seoul, Korea) }\end{array}$ & $\begin{array}{l}\text { Neurologically healthy } \\
\text { adults at university hospital } \\
\text { healthcare center }\end{array}$ & $53.6(20-86)$ & $\mathrm{I}, 588$ & 5.5 & 9.4 & $17.5(>70)$ & & 12 \\
\hline Lee et al (Seoul, Korea) & Normal healthy adults & $49.0 \pm 7.7(20-78)$ & 994 & 5.1 & 19.8 & 43.8 & & 13 \\
\hline
\end{tabular}

Abbreviations: $\mathrm{SBI}$, silent brain infarction; TIA, transient ischemic attack.

essential hypertension (HTN) and normal renal function. ${ }^{16}$ For the patients who underwent hemodialysis, the prevalence of SBI was higher than those of general population (48.8\% vs $9.6 \%, P<0.0001$; mean age $55.6 \pm 12.3 ; \mathrm{n}=175) .{ }^{17}$

As for the mechanism, it was suggested that brain and kidney had similar anatomical and physiological vascular beds, and this could be the reason for SBI. ${ }^{15} \mathrm{HTN}$, especially systolic blood pressure (BP), was strongly correlated with the prevalence of SBI in the patients with CKD. High blood flow is constantly perfused through the low-resistance vascular beds throughout systole and diastole. The authors suggested that the hemodynamic stress to these vascular beds could result in small-vessel injuries to both brain and kidney. ${ }^{15}$

Migraine was also associated with SBI. Among the patients with migraine with aura (MA), $8.1 \%$ of 161 subjects showed silent lesions. The prevalence of SBI was $2.2 \%$ in the subjects with migraine without aura, and $0.7 \%$ in the control subjects (age distribution, 20-60 years). ${ }^{18}$

Carotid artery stenosis was also identified as a predictor of SBI, especially located in basal ganglia $(\mathrm{OR}=3.246$; 95\% CI: $1.116-9.444 ; P=0.0307$; mean age with SD, $63.2 \pm 9.5$ years).${ }^{19}$ Approximately $23 \%$ of the patients with asymptomatic carotid stenosis showed SBI (mean age, 68 years) ${ }^{20}$ The incidences of SBI in the patients with carotid stenosis was approximately $23 \%$ (range, $0 \%-50 \%$ ), which were identified on the diffusion-weighted MRI, whom underwent carotid endarterectomy or carotid artery stenting. ${ }^{1}$ They were mostly reversible on the follow-up imaging. In their results, the incidence was higher in the carotid stenting than endarterectomy ( $29 \%$ vs $10 \%)$.

\section{Distribution of SBI}

The distribution of SBI has been studied in adult subjects, however, not in the elderly. The basal ganglia have been the most prevalent location, followed by subcortical white matter, thalamus, cerebral cortex, and infratentorial regions such as cerebellum and brainstem (Figure 2). .,8,13,21-23 $^{2}$

\section{Pathophysiology of SBI}

There have been scant reports regarding the pathophysiology of SBI. Small vessel disease and cardiogenic or arteriogenic emboli have all been suggested as possible pathophysiologic mechanisms of SBI.

"Small vessel disease" through the occlusion of small, deep, perforating arteries was suggested as a causative mechanism of lacunar infarctions. Its concept and detailed pathologic characteristics were described by Fisher in the postmortem study. ${ }^{24}$ In his article, he showed that most asymptomatic lacunar infarctions were caused by the occlusion of arteries approximately $40-200 \mu \mathrm{m}$ in diameter. Many large arteries that were approximately $200-800 \mu \mathrm{m}$ in diameter could cause the symptomatic ones. Small vessel lesions were characterized by fibrinoid necrosis, loss of normal wall architecture, and mural foam cells.

The majority of SBI is lacunar infarction, ${ }^{8}$ and the absence of lesion-corresponding steno-occlusive changes in major 


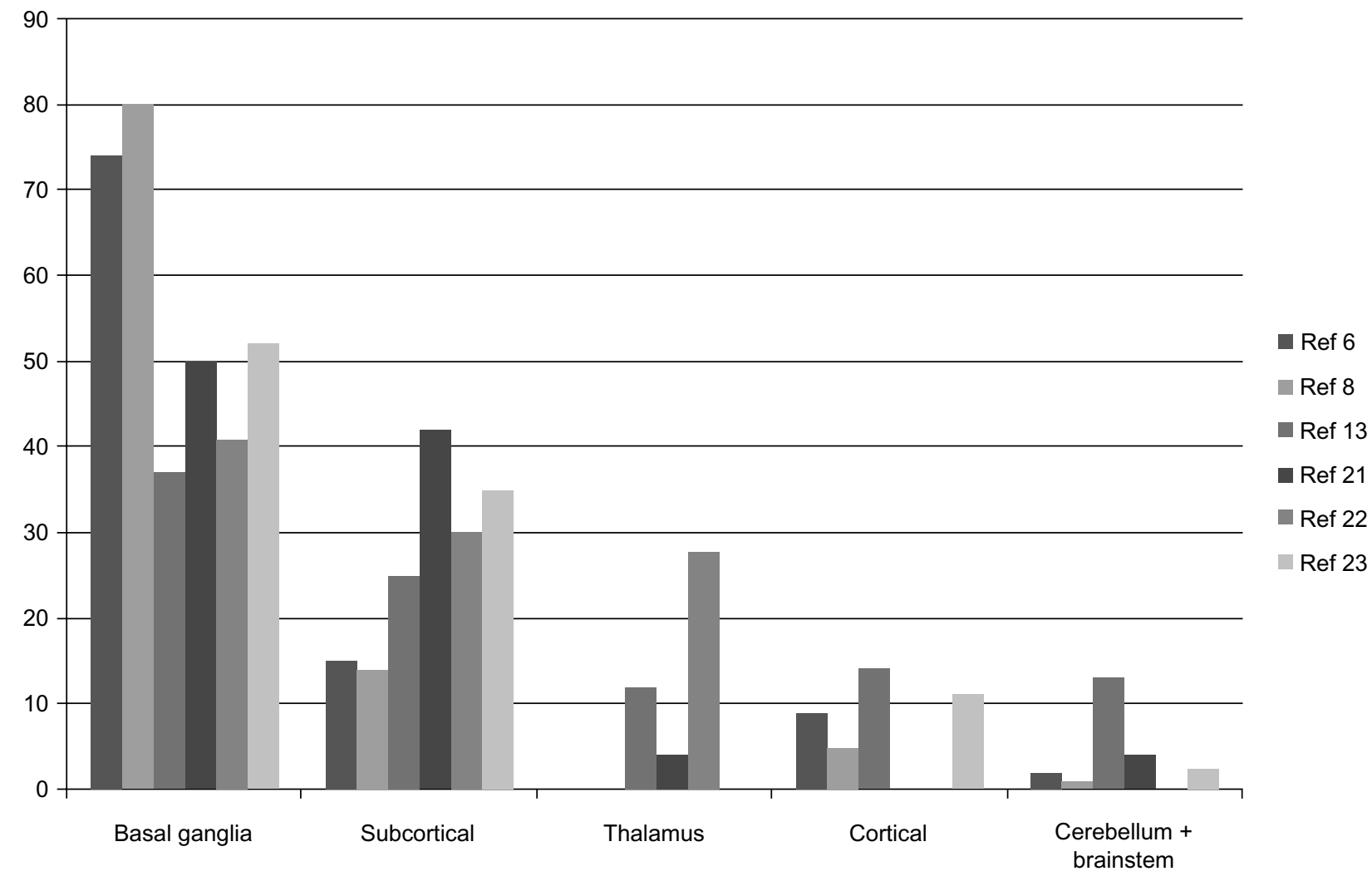

Figure 2 Distribution of SBI.

Note: Distribution of the silent brain infarctions is described in the diagram. The number of vertical lines denotes the frequencies (percent) of corresponding lesions. Abbreviations: SBI, silent brain infarction; ref, references.

vessels and the usual locations of SBI are all the supporting evidences of small vessel disease as a main pathophysiology of SBI. ${ }^{21}$

However, there are conflicting data against this theory. In a recent article with CADASIL (cerebral autosomal dominant arteriopathy with subcortical infarcts and leukoencephalopathy) patients, it has been shown that the lacunar infarctions of leuticular nucleus were caused by hemodynamic change related with impaired cerebral autoregulation, not by small vessel occlusion. ${ }^{25}$

The white matter lesions (WML) also could shed light on the pathophysiology of SBI. It had the significant association with lacunar infartions. ${ }^{26}$ In the Rotterdam Scan Study, the periventricular and subcortical WML in upper tertiles was associated with higher risk of stroke than those in the lowest tertile (hazard ratio $[\mathrm{HR}]=4.7 ; 95 \%$ CI: $2.0-11.2$ and $\mathrm{HR}=3.6 ; 95 \% \mathrm{CI}: 1.4-9.2$, respectively). This association is more stronger in the periventricular WML than those of subcortical ones. ${ }^{27}$ Periventricular WML was suggested to have somewhat different pathophysiology with a subcortical one. ${ }^{28}$ It was suggested that traumatic damage to the loosely arranged network around the ventricle could be caused by increased intracranial pulse pressure based on the alterations in the signal of the ependymal wall through the detailed three-dimensional MR analysis. The lesions also could not show spatial relationship with perforant arteries. Furthermore, the significant arteriolar luminal stenosis or occlusion was not detected in the patients with WML. ${ }^{29}$

In the patients with migraine, the lesions were all located in the junctional regions of the cerebellum. ${ }^{30,31}$ The authors suggested that the combination of migraine attack-related hypoperfusion and embolism could be explanations for it rather than small vessel disease or atherosclerosis. The cerebral blood flow reduction that was up to $7 \%-50 \%$ could be accompanied during the cortical spreading depression in MA. The terminal arteries in cerebellum, which did not have good anastomoses, became narrow in diameter as they enter into the terminal portions in the parenchyma. Superior cerebellar artery is longer than antertior inferior cerebellar artery or posterior inferior cerebellar artery; thus in the case of blood flow reduction, thrombi could be produced easily. Microemboli also could not be washed out and make an occlusion eventually. Besides these, there could be an increment of blood-brain permeability, coagulopathy, and secretion of vasoactive peptides. All these changes could contribute to the occurrence of junctional lesions. In the other 
aspect, the pronounced, prolonged, diffuse hyperperfusion in the migraine patients also could cause rheological barotraumas and pressure diapedesis to the deeper arterioles, and thus eventually cause arterial wall degeneration through lipohyalinosis and fibrinoid necrosis. ${ }^{32}$

Up to now, small vessel occlusion might have been suggested as an important explanation for SBI. However, there were several conflicting data about its role as main pathophysiologic mechanism. There were good reasons supporting that hemodynamic and embolic events also need to be considered.

\section{Risk factors Hypertension}

HTN has been a consistent major risk factor of SBI in various studies. The Rotterdam Scan Study revealed a significant relationship between HTN and SBI after adjusting for age and sex $(\mathrm{OR}=2.4 ; 95 \% \mathrm{CI}: 1.7-3.3) .{ }^{8}$ Other studies reproduced these results in 175 neurologically healthy elderly who were older than 65 years $(\mathrm{OR}=3.54 \text {; 95\% CI: } 1.47-8.59)^{33}$ and in 994 normal healthy adults $(\mathrm{OR}=3.47 ; 95 \% \mathrm{CI}: 1.71-7.03){ }^{13}$

Another interesting factor was systolic and diastolic BP reactivity related with mental stress. In a previous study that enrolled 67 healthy elderly aged between 55 and 81 years, the relationship between the BP reactivity and SBI was evaluated. The systolic and diastolic BP responses to 3 laboratory-based mental stressor were recorded. In their results, those BP reactivities were signficantly related with SBI even after adjusting for the resting BP (systolic BP: $r^{2}=0.14, P=0.004$; diastolic BP: $\left.r^{2}=0.08, P=0.04\right)$. Authors have assumed that the BP response to the various mental stressors was the risk factor of SBI. ${ }^{34}$ Several mechanisms were proposed. Exaggerating BP response was suggested to be a sign of dysregulated autonomic function and thus could be associated with recurrent transient cerebral hypoperfusion. Furthermore, impaired vasomotor reactivity, impaired autoregulation, and following transient vasospasm could represent causes of the silent lesions.

Morning BP surges have also garnered a lot of attention. This was defined as a subtraction from the mean systolic BP during the 2 hours after awakening with mean systolic BP during the 1 hour that included the lowest sleep BP $(n=191$, elderly hypertensive, average age $76 \pm 6.9) .{ }^{35}$ In this study, they divided the subjects into 2 groups with a cutoff value of $55 \mathrm{mmHg}$ and compared the incidence of SBI and overt stroke between the 2 groups. According to their results, the morning surge (MS) group showed a higher prevalence of SBI than the non-MS group after matching for age and 24-hour ambulatory BP (70\% vs 49\%, $P<0.01$ ).
A total of 224 elderly hypertensive subjects older than 60 years were enrolled in another study. ${ }^{36}$ Orthostatic HTN, defined as an increase of over $20 \mathrm{mmHg}$ after standing, revealed a significantly higher prevalence and number of SBI lesions per person compared with the normal group ( $81 \%$ vs $48 \%$; 3.4 per person vs 1.4 per person, $P<0.0001$ ). However, they also showed higher morning BP (159 vs $149 \mathrm{mmHg}$, $P=0.007$ ) and a higher BP variability (standard deviation of awake SBP) than the normal group (21 vs $17 \mathrm{mmHg}$, $P<0.0001)$. Orthostatic hypotension, which was defined as a decrease of over $20 \mathrm{mmHg}$ also indicated a higher number of SBI lesions per person (2.7 vs 1.4 per person) after an adjustment for confounding factors. ${ }^{36}$ Postprandial hypotension, extreme dipping, and increased ambulatory BP variability have been suggested to be associated with SBI. ${ }^{37}$

As for the mechanism, impaired cerebral autoregulation and reduced cardiovascular reserve capacity were proposed. ${ }^{36}$ In the above results, the orthostatic HTN group was older and showed a significantly higher number of left ventricular hypertrophy on electrocardiogram. This might suggest that their longer and more severe history of HTN could have an effect on the prevalence of SBI.

Moreover, ischemic brain lesions could result in the impairment of autonomic nervous system by itself. ${ }^{38}$ The parasympathetic nervous system, which could be evaluated by high-frequency power spectrum (HF), was decreased after acute cerebral infarction. The authors reported that the lacunar infarctions of the putamen or thalamus were associated with these changes. So they suggested that SBI of these locations could contribute to the autonomic dysfunction and also could be an explanation for the unstable BP profiles.

\section{Metabolic syndrome}

Metabolic syndrome consists of high BP, impaired fasting glucose (IFG), high triglyceride (TG) levels, abnormal highdensity lipoprotein (HDL) levels, and increased abdominal circumference (AC). ${ }^{39}$ It has gathered attention because several studies have shown its contribution to major cardiovascular diseases, acting as a major risk factor. A recent study showed its significant relationship with SBI in 1,254 subjects who were older than 65 years $(\mathrm{OR}=1.68 ; 95 \% \mathrm{CI}$ : $1.15-2.44){ }^{40}$ These tendencies were confirmed in middle-aged subjects (adjusted OR [AOR] $=6.52 ; 95 \% \mathrm{CI}: 4.30-9.90$ ) and in normal healthy adults (mean age 53.6 years, ranged from 20 to 86 years; $\mathrm{OR}=2.18 ; 95 \% \mathrm{CI}: 1.38-3.44) .{ }^{12,41}$

Both the full syndrome ( $\geq 3$ of the 5 components) and each of the components were correlated with SBI. It was 
likely that those who have a higher number of components of a metabolic syndrome exhibited more numerous SBI lesions. Among these components, the high BP revealed the strongest correlation with $\mathrm{SBI}(\mathrm{OR}=1.89$; 95\% CI: $1.23-2.91),{ }^{40}$ and the OR of elevated BP was as high as 4.51 compared with 1.25 of low HDL or 1.28 of high TG. ${ }^{12}$ Though only BP and fasting blood glucose level are usually taken into consideration, TG and AC also need to be considered and should be managed properly to prevent the SBI.

Metabolic syndromes can affect the brain in various ways. For example, some studies have shown the inflammatory activity, increased action of free radicals, changes of neurotrophic factors, and reduction of insulin transport into the brain in the patients with metabolic syndrome. ${ }^{42,43}$ It has also been identified as a heterogenous complex that could contribute to both atherothrombotic and lacunar infarctions. ${ }^{44}$ Various components such as HTN, abnormal TG, and obesity could affect the vascular endothelium and thus cause ischemia.

\section{Elevated C-reactive protein}

$\mathrm{C}$-reactive protein (CRP) is an important inflammatory marker and closely related with the occurrence of the cardiovascular diseases. In the Rotterdam Scan Study, 636 elderly aged 60-90 years were followed up for 3.3 years, and it was found that high CRP attributed to the high prevalence and incidence of the incident lacunar infarction although this association was not significant. ${ }^{45}$ Another study, which was conducted prospectively in 194 neurologically healthy subjects (mean age $67.3 \pm 7.5$ ), showed that the mean CRP and interleukin-6 (IL-6) levels of the SBI(+) group was higher than the SBI(-) group. ${ }^{21}$ The prevalence of SBI increased as the level of the inflammatory markers increased (CRP: $\mathrm{OR}=1.85 / \mathrm{SD}$ increase; IL-6: OR $=2.00 / \mathrm{SD}$ increase).

As for the mechanism, inflammatory endothelial activation and dysfunction were observed in the patients with small vessel disease. ${ }^{45-47}$ Chronic inflammation process in the cerebral small vessels was suggested to cause the microangiopathy and eventually ischemia. Further, CRP can be elevated as a response to ischemic tissue damage. ${ }^{21}$

There was another insightful theory regarding the role of CRP in lacunar infarctions and WMLs. ${ }^{45}$ Despite the absence of inflammatory cells in the vessel walls, endothelial inflammation markers such as intercellular adhesion molecules and vascular cell adhesion molecules increased in the lacunar infarctions and WMLs. This suggested that inflammatory endothelial activation had a role in SBI by itself. Neuron and glia also could be more vulnerable to cerebral hypoperfusion due to inflammation through microglial activation. ${ }^{48}$

\section{Hyperhomocysteinemia}

The total pHcy has been suggested as a potential modifiable risk factor of cerebral atherosclerosis, stroke, and dementia. ${ }^{49}$ The arterial wall can be affected and the vascular damage may happen due to hyperhomocysteinemia.

In one particular study, 153 community-dwelling elderly people aged older than 66 years were enrolled, and their pHcy level and MTHFR gene were measured. ${ }^{9}$ They found that SBI was in $24.8 \%$ of subjects. The pHcy level was higher in the $\mathrm{SBI}(+)$ group than in the $\mathrm{SBI}(-)$ group $(13.6 \pm 4.1 \mathrm{mmol} / \mathrm{L}$ vs $11.0 \pm 3.3 \mathrm{mmol} / \mathrm{L}, P=0.0004)$.

The previous results were reproduced in another study of 161 patients with SBI and 126 healthy subjects (mean age $\pm \mathrm{SD} ; 63.02 \pm 11.26$ and $61.98 \pm 10.14$, respectively). ${ }^{50}$ When the total $\mathrm{pHcy}$ level was stratified as high $(\geq 11.77 \mu \mathrm{mol} / \mathrm{L})$, moderate $(8.71-11.76 \mu \mathrm{mol} / \mathrm{L})$, and low $(\leq 8.70 \mu \mathrm{mol} / \mathrm{L})$, the AOR of the high-level pHcy group for $\mathrm{SBI}(\mathrm{AOR}=4.78,95 \% \mathrm{CI}: 2.45-9.33)$ was significantly greater than that of the low group $(\mathrm{AOR}=1.00)$. Besides these, the MTHFR 677TT genotype among the various polymorphisms in the SBI patients showed a significant correlation with increased pHcy level. That group also revealed an inverse correlation between pHcy and folate level. This suggested that folate supplementation in this specific genetic group could reduce the frequency of SBI.

Another cross-sectional study was conducted in the Rotterdam Scan Study for elderly participants aged 60-90 years. ${ }^{49}$ Mean total pHcy level was $11.5 \mu \mathrm{mol} / \mathrm{L}$ $(\mathrm{SD}=4.1)$, and the occurrence of SBI increased with higher total pHcy level after adjustment for cardiovascular risk factors $(\mathrm{OR}=1.24 / \mathrm{SD}$ increase; 95\% CI: 1.06-1.45). These data suggested that the pHcy level could contribute to the subsequent occurrence of SBI.

As for the mechanism, hyperhomocysteinemia could cause the endothelial cell injury, increased platelet aggregation, and abnormalities of the fibrinolysis. ${ }^{51}$ Increased synthesis of thromboxane A2 and decreased synthesis of prostacyclin could cause the increased platelet aggregation. It also could contribute to impaired endothelium-dependent vasodilatation and enhanced lipoprotein(a) binding to fibrin. All these components together might be the causes of increased frequency of SBI in the patients with hyperhomocysteinemia.

\section{Coronary artery disease}

Coronary artery disease (CAD) was analyzed for its correlation with SBI in one study that enrolled 133 CAD patients who underwent coronary angiography (mean age, 65.3 years). ${ }^{52}$ When the patients were stratified into 3 groups 
according to the number of steno-occlusive coronary vessels, the prevalence of SBI was significantly different between each groups (zero-vessel, 27.3\%; one-vessel, 55.6\%; two-vessel, $81.3 \%$; three-vessel, $74.2 \% ; P=0.0002)$. Further, the maximal size and multiplicity of SBI in the two-vessel (1.00 and 1.44) and three-vessel (0.94 and 1.26) groups were significantly higher than those of the zero-vessel $(0.27$ and 0.50) CAD group ( $P=0.0002, P=0.0025$, respectively).

In another study, they used a different approach to reveal the difference in the characteristics and progression of SBI between the HTN and CAD patients. ${ }^{53}$ They studied the location and multiplicity of the SBI in 107 CAD patients who were diagnosed by coronary angiography (mean age, 62 years) and 101 HTN patients who were negative for the history of stroke (mean age, 60 years). The number of multiple SBI carriers who had 3 or more SBI lesions was significantly higher in the CAD plus HTN group than in the HTN-only group ( $46 \%$ vs $21 \%, P=0.001)$. According to multiple logistic regression analysis, the number of involved coronary vessels in CAD patients and the age of the HTN patients were proven as independent determinants of SBI (OR = 2.28, 95\% CI: 1.39-3.76, $P<0.005$; OR = 1.09, 95\% CI: $1.04-1.15, P<0.001$, respectively). In patients with CAD, the SBI of deep perforator territory, such as basal ganglia and thalamus, was significantly associated with the involved vessel number $(P<0.005)$. According to their results, the progression of SBI was more severe in the multivessel CAD and HTN(+) CAD groups than the HTNonly and HTN(-) CAD groups. The severity of the coronary atherosclerosis was also more closely correlated with the SBI of deep perforator territory than that of white matter. In summary, the presence and severity of CAD contributed to the pathologic process of SBI independent of HTN.

With respect to the mechanism, the authors proposed that the risk factors shared by both the coronary heart disease and the ischemic infarcts could be the explanation for their observations. ${ }^{53}$ It was suggested that risk factors such as HTN and old age may cause systemic atherosclerosis and thus result in both CAD and SBI. Microthromboembolism caused by ventricular dysfunction, complicated atrial fibrillation (AF), and carotid artery or aortic arch stenosis was also suggested as a possible pathogenic mechanism of SBI.

\section{Atrial fibrillation}

There have been interesting theories regarding the pathogenesis of SBI in patients with $\mathrm{AF}^{54}$ Japanese researchers compared the incidence of SBI between AF and control groups and found a significant increase in the incidence of SBI in AF patients. Although major cardiovascular risk factors such as HTN and diabetes were more prevalent in AF subjects, the authors focused their attention on the decreased incidence of SBI during a follow-up period after aspirin prescription. Unlike the typical embolic lesions, these were located mainly in the deep perforated sites, and aspirin was able to attenuate the number of lesions. Therefore, the authors assumed their SBI lesions could have resulted from microthrombi, not from embolic events.

In another study, the authors showed that nitric oxide (NO) synthesis could be attenuated by irregular heart rate in AF patients. ${ }^{55,56}$ Vascular endothelium has also been suggested to show sclerotic changes caused by irregular shear stress. ${ }^{57,58}$ Along with this, P-selectin expression on platelets increased. All these changes could contribute to the increased risk of ischemic lesions.

\section{Genetic risk factors}

Besides MTHFR protein described above, there were several genetic risk factors for SBI.

Susceptibilities to SBI and white matter hyperintensities by genetic polymorphisms were studied by several groups. Several genes such as protein kinase $\mathrm{C} \eta(P R K C H)$ gene, angiotensin-converting enzyme (ACE), and apolipoprotein (a) $[\operatorname{apo}(\mathrm{a})]$ were proposed as possible candidates, though results were not consistent throughout the studies. ${ }^{59}$

High concentration of lipoprotein(a) [Lp(a)] can cause dyslipidemic condition and thus finally atherothrombosis. ${ }^{59}$ Furthermore, apo(a) itself might have an effect on the vascular endothelial cell, smooth muscle cell, and monocytes through lipohyalinotic or fibrinoid necrotic change, and finally cause the disintegrity of small arterial wall. ${ }^{59} \mathrm{Apo}(\mathrm{a})$ size polymorphism did not change easily like Lp(a) concentration by a number of environmental factors, such as sex hormone and acute inflammation. In one study, high frequency of apo(a) allele $\mathrm{V}$ that was designated for the combination of alleles I-IV was significantly associated with SBI and symptomatic subcortical infarction; however, it was evident only in the young subjects. ${ }^{59} \mathrm{ACE}$ D/I polymorphism was also suggested as a risk factor of SBI in the several previous reports though the results were conflicting. ${ }^{59}$ This polymorphism might contribute to the plasma and tissue ACE activity and thus cause the disturbance of arterial wall integrity. Lacunar infarction was associated with this polymorphism. ${ }^{60}$ However, in the cases with SBI, ACE D allele showed the various results and there were no definite conclusive data yet. ${ }^{59}$ 
Endothelial nitric oxide synthase (eNOS) gene polymorphism and haplotypes were also suggested as a risk factor of SBI (mean age, 62.22 \pm 11.90 ). ${ }^{61}$ The eNOS 894GT and $894 \mathrm{GT}+\mathrm{TT}$ genotype showed the increased OR for SBI, whereas the $894 \mathrm{GG}$ genotype did not $(\mathrm{OR}=2.00 ; 95 \% \mathrm{CI}$ : $1.30-3.08 ; \mathrm{OR}=2.05,95 \%$ CI: $1.34-3.16$, respectively). This polymorphism was also suggested as a risk factor of the lacunar infarction. ${ }^{62}$ The specific haplotypes, such as -786T4b-894G, -786T-4b-894T, and -786C-4a-894T were more prevalent in the SBI patients. The eNOS involves in the cerebral vasodilation, vascular integrity, and the inhibition of smooth muscle proliferation. ${ }^{63-65}$

Single-nucleotide polymorphism (SNP) of $P R K C H$ gene was associated with SBI (mean age, $66.3 \pm 9.9$ ). ${ }^{66}$ Though exact mechanism was not known yet, 2 SNPs rs3783799 and rs2230500 for AA+AG vs GG, which were common in Asian people, showed the positive association with silent lacunar infarction after adjusting confounding factors $(\mathrm{OR}=1.27$; 95\% CI: 1.09-1.48).

Besides these, the 460Trp allele of the $\alpha$-adducin gene (ADD1) showed positive association with $\mathrm{SBI}$ and subcortical WML (OR $=1.36,95 \%$ CI: $0.98-1.88 ; 1.45$ vs $1.24 \mathrm{~mL}$, $P=0.22$, respectively). ${ }^{67}$

\section{Other considerations}

In addition to earlier mentioned evidences, several other factors need to be considered. Cerebral amyloid angiopathy (CAA) has also been associated with SBI in the elderly. Diffusion-weighted hyperintense lesions were evaluated in 78 patients with CAA (mean age, 78.2 \pm 8.9 ) and 55 patients with Alzehiemer disease/ mild cognitive impairment (mean age, $81.4 \pm 8.1$ ). ${ }^{68}$ The former showed $15 \%$ asymptomatic subacute cerebral infarctions mainly in the cortex and subcortical white matter. The results also revealed a higher median number of total hemorrhages in the former group compared with the latter despite no differences in the vascular risk factors ( $22 \mathrm{vs} 4, P=0.025$ ).

Body mass index (BMI) was also correlated with the occurrence of SBI. ${ }^{33}$ It is easy to measure and relate with the several metabolic and cardiovascular diseases, so its correlation with SBI could be assumed. According to the presence of SBI, there were significant differences in the BMI level (SBI(-) group: $20.8 \pm 3.2 \mathrm{~kg} / \mathrm{m}^{2} ; \mathrm{SBI}(+)$ group: $\left.22.1 \pm 3.2 \mathrm{~kg} / \mathrm{m}^{2}\right)$, especially in those older than 81 years $\left(19.6 \pm 2.6 \mathrm{~kg} / \mathrm{m}^{2}\right.$ vs $21.2 \pm 2.8 \mathrm{~kg} / \mathrm{m}^{2}$ ).

There was one report that studied the relationship between psychiatric diseases and SBI. ${ }^{69}$ In this study, 194 adult patients (mean age, $48 \pm 9.7$ years) who were treated for various psychiatric diseases were included. The prevalence of SBI was 3.6\% based on CT scanning, and the patients with SBI mostly had been treated for the postconcussion syndrome $(53.3 \%)$ and depression (42.8\%). However, we could not find any studies that were designed for the elderly. ${ }^{69}$

There were scant reports regarding the evaluation of protective factors. In one interesting study, mild alcohol consumption was proven as an independent protective factor for SBI $(\mathrm{OR}=0.31 ; 95 \% \mathrm{CI}: 0.12-0.78) .{ }^{13}$ However, this tendency was

Table 2 Odds ratio of major risk factors for SBI in the elderly

\begin{tabular}{|c|c|c|c|c|c|}
\hline & & \multicolumn{3}{|l|}{ Risk of SBI } & \multirow[t]{2}{*}{ Reference } \\
\hline & & Crude OR $(95 \% \mathrm{Cl})$ & Adjusted OR $(95 \% \mathrm{CI})$ & & \\
\hline \multirow[t]{2}{*}{ Hypertension } & & $2.4(1.7 \sim 3.3)$ & & & 8 \\
\hline & & & $3.47(I .7 \mid \sim 7.03)$ & & 13 \\
\hline Metabolic & Overall & $2.74(1.76 \sim 4.26)^{12}$ & $2.18(1.38 \sim 3.44)^{12}$ & $1.68(1.15 \sim 2.44)^{40}$ & 12,40 \\
\hline \multirow[t]{5}{*}{ syndrome } & Elevated BP & $4.51(2.53 \sim 8.04)^{12}$ & $3.75(2.05 \sim 6.85)^{12}$ & $1.89(1.23 \sim 2.91)^{40}$ & \\
\hline & IFG & $2.02(1.29 \sim 3.07)^{12}$ & $1.74(1.08 \sim 2.80)^{12}$ & $1.35(0.96 \sim 1.91)^{40}$ & \\
\hline & High TG & $1.28(0.77 \sim 2.1 \mathrm{I})^{12}$ & $1.54(0.9 \mathrm{I} \sim 2.6 \mathrm{I})^{12}$ & $1.39(0.89 \sim 2.17)^{40}$ & \\
\hline & Low HDL & $1.25(0.76 \sim 2.06)^{12}$ & $1.08(0.64 \sim 1.82)^{12}$ & $0.84(0.58 \sim 1.22)^{40}$ & \\
\hline & Large WC & $0.92(0.59 \sim 1.45)^{12}$ & $0.70(0.41 \sim 1.18)^{12}$ & $1.23(0.72 \sim 2.09)^{40}$ & \\
\hline Elevated CRP & & $1.85(1.29 \sim 2.63)$ & $1.50(1.00 \sim 2.24)$ & & 21 \\
\hline Elevated IL-6 & & $2.00(1.39 \sim 2.88)$ & $1.85(1.24 \sim 2.78)$ & & 21 \\
\hline Hyperhomocysteinemia & & & $1.24(1.06 \sim 1.45)$ & & 49 \\
\hline No. of involved CA in & & & $2.28(1.39 \sim 3.76)$ & & 53 \\
\hline \multicolumn{6}{|l|}{ coronary artery disease } \\
\hline BMI & & & $0.89(0.79 \sim 0.98)$ & & 33 \\
\hline Alcohol consumption & & & $0.3 \mathrm{I}(0.12 \sim 0.78)$ & & 13 \\
\hline
\end{tabular}

Abbreviations: SBI, silent brain infarction; OR, odds ratio; Cl, confidential interval; BP, blood pressure; IFG, impaired fasting glucose; TG, triglycerides; HDL, high-density lipoprotein; WC, waist circumference; CRP, C-reactive protein; IL, interleukin; CA, coronary artery; BMI, body mass index. 
not valid in those who were older than 50 years. There were some explanations for this protective effect of mild to moderate alcohol consumption. For example, the HDL-cholesterol level, especially HDL-2 and HDL-3 level, could increase through alcohol consumption..$^{70,71}$ Also, the coagulation pathway might be influenced by alcohol. However, the authors failed to show a significant difference of HDL-cholesterol or serum fibrinogen level in their study population. ${ }^{13}$ Also, these results need to be reproduced in the elderly population.

There were controversial results between SBI and another important habitual factor, smoking. Smoking showed positive correlation with the multiplicity of SBI $\left(r^{2}=0.34 ; P<0.001\right)$ among Japanese subjects who had several vascular risk factors (mean age, 67.2 years). ${ }^{72}$ Current smokers had more number of silent lesions than the ex-smokers $(1.9 \pm 2.2$ vs $0.5 \pm 0.8, P<0.01)$. In another Japanese study that enrolled neurologically healthy adults (mean age, $60.9 \pm 7.3$ years), there was no significant associations between smoking and the incidence of SBI. ${ }^{73}$ In larger western population who aged 55-70 years, there were a significant relationship between the exposure of tobacco and the presence of SBI. ${ }^{74}$ The OR for each nonsmokers who were exposed to the tobacco smoke, past smokers, and current smokers increased in the order $(\mathrm{OR}=1.06,1.16$, and 1.88; 95\% CI: 0.64-1.75, 0.74-1.83, and $1.13-3.13$, respectively). In addition, especially in the patients who underwent hemodialysis, smoking habit was identified as an independent risk factor for SBI $\left(r^{2}=0.378\right.$; $P<0.0001) .{ }^{17}$ In summary, there was not a conclusive data about this association until now.

\section{Clinical signficance Clinically overt stroke}

The relationship between SBI and clinically overt stroke is one of the main concerns for both physicians and patients. A cardiovascular health study was conducted prospectively on 3,324 subjects who did not have a history of stroke. ${ }^{5}$ During the 4-year follow-up, $28 \%$ of subjects exhibited SBIs, and there was a significant difference in the stroke incidence between $\mathrm{SBI}(+)$ and $\mathrm{SBI}(-)$ groups (18.7 per 1000 person-years vs 9.5; $\mathrm{HR}=1.5$; 95\% CI: 1.1-2.1). The median age of those who underwent MRI were 73.0 and 77.0 years, respectively. Those who had multiple silent infarctions exhibited a higher adjusted relative risk for the further overt stroke $(\mathrm{HR}=1.9 ; 95 \% \mathrm{CI}: 1.2-2.8)$. In the $\mathrm{SBI}(+)$ group, the following were the main determinants for the risk of stroke: diastolic and systolic BP, common and internal carotid wall thickness, and the presence of AF.

With respect to the general population, another study recruited 933 neurologically healthy subjects who were aged 30-81 (mean age, $57.5 \pm 9.2$ years) and followed up for $1-7$ years. $^{2}$ The prevalence of SBI was $10.6 \%$. The annual incidence of stroke was higher in the $\mathrm{SBI}(+)$ group than SBI(-) group (10.1\% vs $0.77 \%)$. The OR for the clinical stroke was 10.48 (95\% CI: 3.63-30.21).

The impact of SBI on cerebral hemorrhage has not been clearly evaluated until now. This could be examined by reviewing studies focused on both SBI and cerebral microbleeds (cMBs). The association between SBI and cMBs were suggested in one cross-sectional study. ${ }^{75}$ The prevalence of cMBs in normal healthy subjects was $5.6 \%$ (mean age, $67.6 \pm 7.8$ years; range, 38-91). Among the various risk factors, silent lacunar infarction was a major risk factor for the occurrence of cMBs (OR = 5.813; 95\% CI: 2.037-16.59; $P=0.001)$. As the cMBs were suggested as a risk factor for cerebral hemorrhage, we could assume the correlation between SBI and cerebral hemorrhage. However, the authors did not comment on this possibility.

\section{Dementia and cognitive decline}

As a subset of the Rotterdam Scan Study, a neuropsychological test and MRI were performed twice from 1995 to 1996 and from 1999 to 2000 in 1,015 elderly who had no history of stroke or dementia. ${ }^{76}$ In their results, the presence of baseline SBI doubled the risk of subsequent dementia in a period averaging 3.6 years $(\mathrm{HR}=2.26$; 95\% CI: $1.09-4.70)$ and was correlated with a steeper decline in global cognitive function. Among the silent lesions, the thalamic infarctions were associated with a decline in the memory performance and the nonthalamic infarctions in the psychomotor speed. When the baseline $\mathrm{SBI}(+)$ group was stratified according to the presence of additional silent infarctions, the cognitive decline was confined to those who had additional ones.

In another study, the subcortical ischemic vascular disease group, which was characterized by multiple silent lacunar infarctions, showed poor executive function on a robust neuropsychological test. ${ }^{22}$ A total of 94 healthy elderly subjects aged $\geq 55$ years were recruited and $33 \%$ of them had lacunar infarctions. The executive function was inversely correlated with the number of subcortical lacunar infarctions. These findings emphasize the need for early detection and prevention of such lesions.

\section{Depression}

Depressive state or major depression is a risk factor and a consequence of SBI. There were a scant number of papers that mentioned the relationship between depression and SBI in a prospective way. However, there was evidence that suggested 
the contribution of SBI to the occurrence of depression. ${ }^{77}$ Patients with presenile and senile major depression showed an unusually high incidence of SBI (65.9\% and 93.7\%, respectively), suggesting their contribution to the occurrence of organic depression. The authors insisted that $>50 \%$ of presenile-onset and senile-onset major depression was associated with SBI and that such patients should be prescribed antiplatelets for the prevention of overt stroke.

\section{Aspiration pneumonia}

One interesting study showed that SBI could contribute not only stroke or dementia but also general medical conditions such as pneumonia. ${ }^{78}$ A total of 269 community-dwelling elderly without any history of stroke were followed up for 2 years. After CT scans, they were divided into 2 groups according to the presence of silent ischemic lesion. The $\mathrm{SBI}(+)$ group showed 4 times higher prevalence of pneumonia than the $\mathrm{SBI}(-)$ group over a 2 -year period $(\mathrm{OR}=4.67$; $95 \% \mathrm{CI}$ : 1.87-11.67; $P<0.01)$.

Similar results were reproduced in another cross-sectional study for the patients with Alzheimer disease. ${ }^{79}$ A total of 121 elderly were included (mean age with $\mathrm{SD}, 78.2 \pm 7.5$; male/female ratio $=48 / 73$ ). The association between the aspiration pneumonia and the following risk factors were evaluated: age, gender, severity of dementia, SBI in the basal ganglia, and the use of psychotropic drugs (neuroleptics and benzodiazepines). Aspiration pneumonia was more prevalent in those who had SBI and severe dementia, and the use of neuroleptics was also associated with aspiration pneumonia. In their conclusion, it has been recommended that physicians should be aware of the risk of aspiration pneumonia in patients with severe Alzheimer disease, who had SBI in that basal ganglia and took neuroleptics.

\section{Treatment and prevention}

There have been no guidelines or consensus regarding the treatment of SBI. As their contribution to overt stroke and dementia becomes evident, the efforts to manage the underlying risk factors should be emphasized. Also, the risk of aspiration pneumonia needs to be considered. There is theoretical background for the use of statins, NSAIDs, and aspirin, which could reduce inflammatory activity and prevent the thrombotic process. ${ }^{45}$ However, there have been no supporting clinical trials for these practices.

\section{Perspectives}

SBI has the clinical significance as a target organ damage caused by various underlying risk factors and also as a prodrome for various overt diseases such as stroke and dementia. With the increasing number of elderly, early detection and control of risk factors should be emphasized. A comment in a recent article that "covert" is a more appropriate term than "silent" needs to be seriously considered.

\section{Disclosure}

We have no relevant financial interest in this manuscript.

\section{References}

1. Vermeer SE, Longstreth WT Jr, Koudstaal PJ. Silent brain infarcts: a systematic review. Lancet Neurol. 2007;6:611-619.

2. Kobayashi S, Okada K, Koide H, Bokura H, Yamaguchi S. Subcortical silent brain infarction as a risk factor for clinical stroke. Stroke. 1997;28: 1932-1939.

3. Bokura H, Kobayashi S, Yamaguchi S. Distinguishing silent lacunar infarction from enlarged Virchow-Robin spaces: a magnetic resonance imaging and pathological study. J Neurol. 1998;245:116-122.

4. Wahlund LO, Barkhof F, Fazekas F, et al. A new rating scale for agerelated white matter changes applicable to MRI and CT. Stroke. 2001; 32:1318-1322.

5. Bernick C, Kuller L, Dulberg C, et al. Silent MRI infarcts and the risk of future stroke: the cardiovascular health study. Neurology. 2001;57: 1222-1229.

6. Vermeer SE, Den Heijer T, Koudstaal PJ, Oudkerk M, Hofman A, Breteler MM. Incidence and risk factors of silent brain infarcts in the population-based Rotterdam Scan Study. Stroke. 2003;34:392-396.

7. Longstreth WT Jr, Dulberg C, Manolio TA, et al. Incidence, manifestations, and predictors of brain infarcts defined by serial cranial magnetic resonance imaging in the elderly: the cardiovascular health study. Stroke. 2002;33:2376-2382.

8. Vermeer SE, Koudstaal PJ, Oudkerk M, Hofman A, Breteler MM Prevalence and risk factors of silent brain infarcts in the populationbased Rotterdam Scan Study. Stroke. 2002;33:21-25.

9. Matsui T, Arai H, Yuzuriha T, et al. Elevated plasma homocysteine levels and risk of silent brain infarction in elderly people. Stroke. 2001; 32:1116-1119.

10. Shinkawa A, Ueda K, Kiyohara Y, et al. Silent cerebral infarction in a community-based autopsy series in Japan. The Hisayama Study. Stroke. 1995;26:380-385.

11. Giele JL, Witkamp TD, Mali WP, van der GraafY. Silent brain infarcts in patients with manifest vascular disease. Stroke. 2004;35:742-746.

12. Kwon HM, Kim BJ, Lee SH, Choi SH, Oh BH, Yoon BW. Metabolic syndrome as an independent risk factor of silent brain infarction in healthy people. Stroke. 2006;37:466-470.

13. Lee SC, Park SJ, Ki HK, et al. Prevalence and risk factors of silent cerebral infarction in apparently normal adults. Hypertension. 2000;36: 73-77.

14. Wada M, Nagasawa $H$, Iseki $C$, et al. Cerebral small vessel disease and chronic kidney disease (CKD): results of a cross-sectional study in community-based Japanese elderly. J Neurol Sci. 2008;272:36-42.

15. Kobayashi M, Hirawa N, Yatsu K, et al. Relationship between silent brain infarction and chronic kidney disease. Nephrol Dial Transplant. 2009;24:201-207.

16. Kobayashi S, Ikeda T, Moriya H, Ohtake T, Kumagai H. Asymptomatic cerebral lacunae in patients with chronic kidney disease. Am J Kidney Dis. 2004;44:35-41.

17. Nakatani $T$, Naganuma $T$, Uchida J, et al. Silent cerebral infarction in hemodialysis patients. Am J Nephrol. 2003;23:86-90.

18. Kruit MC, van Buchem MA, Hofman PA, et al. Migraine as a risk factor for subclinical brain lesions. JAMA. 2004;291:427-434.

19. Uehara T, Tabuchi M, Mori E. Risk factors for silent cerebral infarcts in subcortical white matter and basal ganglia. Stroke. 1999;30:378-382. 
20. Mathiesen EB, Waterloo K, Joakimsen O, Bakke SJ, Jacobsen EA, Bonaa KH. Reduced neuropsychological test performance in asymptomatic carotid stenosis: The Tromso Study. Neurology. 2004;62: 695-701.

21. Hoshi T, Kitagawa K, Yamagami H, Furukado S, Hougaku H, Hori M. Relations of serum high-sensitivity C-reactive protein and interleukin-6 levels with silent brain infarction. Stroke. 2005;36:768-772.

22. Carey CL, Kramer JH, Josephson SA, et al. Subcortical lacunes are associated with executive dysfunction in cognitively normal elderly. Stroke. 2008;39:397-402.

23. Das RR, Seshadri S, Beiser AS, et al. Prevalence and correlates of silent cerebral infarcts in the framingham offspring study. Stroke. 2008;39:2929-2935.

24. Fisher. Lacunar infarcts - a review. Cerebrovasc Dis. 1991;1:311-320.

25. Miao Q, Paloneva T, Tuisku S, et al. Arterioles of the lenticular nucleus in CADASIL. Stroke. 2006;37:2242-2247.

26. Vermeer SE, Hollander M, van Dijk EJ, Hofman A, Koudstaal PJ, Breteler MM. Silent brain infarcts and white matter lesions increase stroke risk in the general population: the Rotterdam Scan Study. Stroke. 2003;34:1126-1129.

27. Oh SH, Kim NK, Kim SH, et al. The prevalence and risk factor analysis of silent brain infarction in patients with first-ever ischemic stroke. J Neurol Sci. 2010;293:97-101.

28. Henry Feugeas MC, de Marco G, Peretti II, Godon-Hardy S, Fredy D, Claeys ES. Age-related cerebral white matter changes and pulse-wave encephalopathy: observations with three-dimensional MRI. Magn Reson Imaging. 2005;23:929-937.

29. Fernando MS, Simpson JE, Matthews F, et al. White matter lesions in an unselected cohort of the elderly: Molecular pathology suggests origin from chronic hypoperfusion injury. Stroke. 2006;37:1391-1398.

30. Kruit MC, Launer LJ, van Buchem MA, Terwindt GM, Ferrari MD. MRI findings in migraine. Rev Neurol (Paris). 2005;161:661-665.

31. Kruit MC, Launer LJ, Ferrari MD, van Buchem MA. Infarcts in the posterior circulation territory in migraine. The population-based MRI CAMERA study. Brain. 2005;128:2068-2077.

32. Gupta V. Silent or non-clinical infarct-like lesions in the posterior circulation territory in migraine: brain hypoperfusion or hyperperfusion? Brain. 2006;129:E39.

33. Kotani K, Osaki Y, Sakane N, Adachi S, IshimaruY. Risk factors for silent cerebral infarction in the elderly. Arch Med Res. 2004;35:522-524.

34. Waldstein SR, Siegel EL, Lefkowitz D, et al. Stress-induced blood pressure reactivity and silent cerebrovascular disease. Stroke. 2004; 35:1294-1298.

35. Kario K, Pickering TG, Umeda Y, et al. Morning surge in blood pressure as a predictor of silent and clinical cerebrovascular disease in elderly hypertensives: a prospective study. Circulation. 2003;107:1401-1406.

36. Kario K, Eguchi K, Hoshide S, et al. U-curve relationship between orthostatic blood pressure change and silent cerebrovascular disease in elderly hypertensives: orthostatic hypertension as a new cardiovascular risk factor. J Am Coll Cardiol. 2002;40:133-141.

37. Kario K, Pickering TG. Blood pressure variability in elderly patients. Lancet. 2000;355:1645-1646.

38. Kuriyama N, Mizuno T, Niwa F, Watanabe Y, Nakagawa M. Autonomic nervous dysfunction during acute cerebral infarction. Neurol Res. Epub 2009 Sep 1.

39. Expert Panel on Detection, Evaluation, and Treatment of High Blood Cholesterol in Adults. Executive summary of the third report of the National Cholesterol Education Program (NCEP) expert panel on detection, evaluation and treatment of high blood cholesterol in adults (adult treatment panel III). J Am Med Assoc. 2001;285:2486-2497.

40. Kwon HM, Kim BJ, Park JH, et al. Significant association of metabolic syndrome with silent brain infarction in elderly people. J Neurol. 2009; 256:1825-1831.

41. Park K, Yasuda N, Toyonaga S, Tsubosaki E, Nakabayashi H, Shimizu K. Significant associations of metabolic syndrome and its components with silent lacunar infarction in middle aged subjects. J Neurol Neurosurg Psychiatry. 2008;79:719-721.
42. Gazdzinski S, Kornak J, Weiner MW, Meyerhoff DJ. Body mass index and magnetic resonance markers of brain integrity in adults. Ann Neurol. 2008;63:652-657.

43. Lusis AJ, Attie AD, Reue K. Metabolic syndrome: From epidemiology to systems biology. Nat Rev Genet. 2008;9:819-830.

44. Kawamoto R, Tomita H, Oka Y, Kodama A. Metabolic syndrome as a predictor of ischemic stroke in elderly persons. Intern Med. 2005;44: 922-927.

45. van Dijk EJ, Prins ND, Vermeer SE, et al. C-reactive protein and cerebral small-vessel disease: the Rotterdam Scan Study. Circulation. 2005;112:900-905.

46. Fassbender K, Bertsch T, Mielke O, Muhlhauser F, Hennerici M. Adhesion molecules in cerebrovascular diseases. Evidence for an inflammatory endothelial activation in cerebral large- and small-vessel disease. Stroke. 1999;30:1647-1650.

47. Hassan A, Hunt BJ, O'Sullivan M, et al. Markers of endothelial dysfunction in lacunar infarction and ischaemic leukoaraiosis. Brain. 2003;126:424-432.

48. Dirnagl U, Iadecola C, Moskowitz MA. Pathobiology of ischaemic stroke: An integrated view. Trends Neurosci. 1999;22:391-397.

49. Vermeer SE, van Dijk EJ, Koudstaal PJ, et al. Homocysteine, silent brain infarcts, and white matter lesions: the Rotterdam Scan Study. Ann Neurol. 2002;51:285-289.

50. Kim NK, Choi BO, Jung WS, Choi YJ, Choi KG. Hyperhomocysteinemia as an independent risk factor for silent brain infarction. Neurology. 2003;61:1595-1599.

51. Stein JH, McBride PE. Hyperhomocysteinemia and atherosclerotic vascular disease: pathophysiology, screening, and treatment off. Arch Intern Med. 1998;158:1301-1306.

52. Uekita K, Hasebe N, Funayama N, et al. Cervical and intracranial atherosclerosis and silent brain infarction in Japanese patients with coronary artery disease. Cerebrovasc Dis. 2003;16:61-68.

53. Hoshide S, Kario K, Mitsuhashi T, et al. Different patterns of silent cerebral infarct in patients with coronary artery disease or hypertension. Am J Hypertens. 2001;14:509-515.

54. Sato H, Koretsune Y, Fukunami M, et al. Aspirin attenuates the incidence of silent brain lesions in patients with nonvalvular atrial fibrillation. Circ J. 2004;68:410-416.

55. Minamino T, Kitakaze M, Sato H, et al. Plasma levels of nitrite/nitrate and platelet cGMp levels are decreased in patients with atrial fibrillation. Arterioscler Thromb Vasc Biol. 1997;17:3191-3195.

56. Minamino T, Kitakaze M, Sanada S, et al. Increased expression of P-selectin on platelets is a risk factor for silent cerebral infarction in patients with atrial fibrillation: role of nitric oxide. Circulation. 1998;98:1721-1727.

57. Noris M, Morigi M, Donadelli R, et al. Nitric oxide synthesis by cultured endothelial cells is modulated by flow conditions. Circ Res. 1995;76: 536-543.

58. Topper JN, Cai J, Falb D, Gimbrone MA Jr. Identification of vascular endothelial genes differentially responsive to fluid mechanical stimuli: cyclooxygenase-2, manganese superoxide dismutase, and endothelial cell nitric oxide synthase are selectively up-regulated by steady laminar shear stress. Proc Natl Acad Sci U S A. 1996;93: 10417-10422.

59. Notsu Y, Nabika T, Park HY, Masuda J, Kobayashi S. Evaluation of genetic risk factors for silent brain infarction. Stroke. 1999;30: 1881-1886.

60. Markus HS, Barley J, Lunt R, et al. Angiotensin-converting enzyme gene deletion polymorphism. A new risk factor for lacunar stroke but not carotid atheroma. Stroke. 1995;26:1329-1333.

61. Song J, Kim OJ, Kim HS, et al. Endothelial nitric oxide synthase gene polymorphisms and the risk of silent brain infarction. Int J Mol Med. 2010;25:819-823.

62. Elbaz A, Poirier O, Moulin T, Chedru F, Cambien F, Amarenco P. Association between the Glu298Asp polymorphism in the endothelial constitutive nitric oxide synthase gene and brain infarction. The GENIC investigators. Stroke. 2000;31:1634-1639. 
63. Garg UC, Hassid A. Nitric oxide-generating vasodilators and 8-bromocyclic guanosine monophosphate inhibit mitogenesis and proliferation of cultured rat vascular smooth muscle cells. J Clin Invest. 1989;83: 1774-1777.

64. Kubes P, Suzuki M, Granger DN. Nitric oxide: an endogenous modulator of leukocyte adhesion. Proc Natl Acad Sci U S A. 1991;88: 4651-4655.

65. Wolf A, Zalpour C, Theilmeier G, et al. Dietary l-arginine supplementation normalizes platelet aggregation in hypercholesterolemic humans. J Am Coll Cardiol. 1997;29:479-485.

66. Serizawa M, Nabika T, Ochiai Y, et al. Association between PRKCH gene polymorphisms and subcortical silent brain infarction. Atherosclerosis. 2008;199:340-345

67. van Rijn MJ, Bos MJ, Yazdanpanah M, et al. Alpha-adducin polymorphism, atherosclerosis, and cardiovascular and cerebrovascular risk. Stroke. 2006;37:2930-2934.

68. Kimberly WT, Gilson A, Rost NS, et al. Silent ischemic infarcts are associated with hemorrhage burden in cerebral amyloid angiopathy. Neurology. 2009;72:1230-1235.

69. Avdibegovic E, Becirovic E, Selimbasic Z, Hasanovic M, Sinanovic O Cerebral cortical atrophy and silent brain infarcts in psychiatric patients. Psychiatr Danub. 2007;19:49-55.

70. Handa K, Sasaki J, Saku K, Kono S, Arakawa K. Alcohol consumption, serum lipids and severity of angiographically determined coronary artery disease. Am J Cardiol. 1990;65:287-289.
71. Rimm EB, Giovannucci EL, Willett WC, et al. Prospective study of alcohol consumption and risk of coronary disease in men. Lancet. 1991; 338:464-468.

72. Eguchi K, Kario K, Hoshide S, et al. Smoking is associated with silent cerebrovascular disease in a high-risk Japanese community-dwelling population. Hypertens Res. 2004;27:747-754.

73. Yamashita K, Kobayashi S, Yamaguchi S, Koide H. Cigarette smoking and silent brain infarction in normal adults. Intern Med. 1996;35:704-706.

74. Howard G, Wagenknecht LE, Cai J, Cooper L, Kraut MA, Toole JF. Cigarette smoking and other risk factors for silent cerebral infarction in the general population. Stroke. 1998;29:913-917.

75. Igase $\mathrm{M}$, Tabara $\mathrm{Y}$, Igase $\mathrm{K}$, et al. Asymptomatic cerebral microbleeds seen in healthy subjects have a strong association with asymptomatic lacunar infarction. Circ J. 2009;73:530-533.

76. Vermeer SE, Prins ND, den Heijer T, Hofman A, Koudstaal PJ, Breteler MM. Silent brain infarcts and the risk of dementia and cognitive decline. $N$ Engl J Med. 2003;348:1215-1222.

77. Fujikawa T, Yamawaki S, Touhouda Y. Incidence of silent cerebral infarction in patients with major depression. Stroke. 1993;24:1631-1634.

78. Nakagawa T, Sekizawa K, Nakajoh K, Tanji H, Arai H, Sasaki H. Silent cerebral infarction: a potential risk for pneumonia in the elderly. J Intern Med. 2000;247:255-259.

79. Wada H, Nakajoh K, Satoh-Nakagawa T, et al. Risk factors of aspiration pneumonia in Alzheimer's disease patients. Gerontology. 2001; 47:271-276
Clinical Interventions in Aging

\section{Publish your work in this journal}

Clinical Interventions in Aging is an international, peer-reviewed journal focusing on evidence-based reports on the value or lack thereof of treatments intended to prevent or delay the onset of maladaptive correlates of aging in human beings. This journal is indexed on PubMed Central, MedLine, the American Chemical Society's 'Chemical Abstracts Ser-

\section{Dovepress}

vice' (CAS), Scopus and the Elsevier Bibliographic databases. The manuscript management system is completely online and includes a very quick and fair peer-review system, which is all easy to use. Visit http://www.dovepress.com/testimonials.php to read real quotes from published authors. 